\title{
Uterine artery Doppler analysis at 11-14 weeks as a predictor of intra-uterine growth restriction
}

\section{Uttara Gupta, Usha Agrawal*}

Department of Obstetrics and Gyanecology, People's College of Medical Science and Research Centre, Bhopal, Madhya Pradesh, India

Received: 21 July 2021

Accepted: 16 October 2021

\section{*Correspondence:}

Dr. Usha Agrawal,

E-mail: ushajai2007@yahoo.co.in

Copyright: ( $\subseteq$ the author(s), publisher and licensee Medip Academy. This is an open-access article distributed under the terms of the Creative Commons Attribution Non-Commercial License, which permits unrestricted non-commercia 1 use, distribution, and reproduction in any medium, provided the original work is properly cited.

\section{ABSTRACT}

Background: Successful pregnancy results from reciprocity between placental and maternal cardiovascular system. Intra-uterine growth restriction (IUGR) is a condition which arises from insufficiency of placenta and can be seen as variations in waveforms in uterine artery (UtA). In our study, we studied, whether predictive accuracy of various UtA Doppler indices for IUGR in first trimester early enough to provide an intervention for prevention of IUGR, as it was a leading cause of neonatal morbidity and mortality.

Methods: The study design was a prospective observational study. UtA Doppler was done at 11-14 weeks in 120 pregnancies attending the outpatient and inpatient department of obstetrics and gynaecology, PCMS, Bhopal. The left and right UtA velocity waveforms were studied. Mean pulsatility index (PI), mean resistive index (RI) and diastolic notch were noted. Results obtained were analyzed and tabulated.

Results: Amongst these, 25.86\% developed IUGR. First trimester UtA mean RI and PI were remarkably elevated in patients who developed IUGR on follow up. No relationship was noted between diastolic notch and IUGR. Mean RI and PI were found to be good predictors of IUGR. Using receiver operating characteristics (ROC) curve, the best cutoff of mean RI and mean PI to detect IUGR was 0.68 and 1.56 respectively.

Conclusions: UtA Doppler at 11-14 weeks of gestation recognizes a huge proportion of women who will develop IUGR.

Keywords: Uterine artery Doppler, IUGR, Pulsatility index, Resistance index

\section{INTRODUCTION}

IUGR is associated with a high risk of perinatal mortality and morbidity. ${ }^{1-3}$ It is a result of abnormal placenta formation involving abnormal trophoblast invasion of spiral arteries and a reduction in vascular resistance in the utero-placental circulation. ${ }^{4-6}$ IUGR is usually evident in second to third trimester of pregnancy, but their underlying pathology probably begins in the first trimester. ${ }^{4,7-9}$ Timely prediction is therefore paramount to provide appropriate antenatal surveillance and therapy to improve perinatal outcomes.
Many previous studies have demonstrated an association between second trimester uterine artery Doppler RI and the subsequent development of IUGR. ${ }^{10-14}$ However, there is evidence to demonstrate that trophoblast invasiveness is maximal in the first trimester, when it is also possible to assess uterine artery blood flow by Doppler. ${ }^{15}$

UtA Doppler velocimetry has revolutionized the investigation of the developing placental vasculature showing that impedance to flow in the uterine arteries decreases with the gestational age in normal pregnancy. ${ }^{16}$ But this impedance to flow is increased in established pre- 
eclampsia and IUGR even before the clinical signs of the disease are seen. ${ }^{17,18}$

So, this study was designed to focus on the employment of Doppler ultrasound in the first trimester which may provide an excellent opportunity to screen for these pregnancy complications at an early stage, when intervention might be possible to improve pregnancy outcome. The aim of this study was to investigate the role of colour Doppler in first trimester of pregnancy in predicting IUGR.

\section{METHODS}

This was a prospective observational study conducted from November 2019 to October 2020 on 120 women with singleton pregnancy, between 11-14 weeks of gestation, either admitted or coming for routine antenatal check-up in outdoor patient department of People's college of medical sciences and research center, Bhopal and the subjects were followed till delivery. All women undergoing routine first trimester nuchal translucency ultrasound assessment were offered the option to participate in the study.

\section{Inclusion criteria}

Patients with singleton pregnancy and gestational age between 11-14 weeks were included in the study.

\section{Exclusion criteria}

Patients with fetus sonographically detected congenital anomaly (anencephaly, meningomyelocele), women with systemic illness like chronic hypertension, renal disease and diabetes mellitus, multiple pregnancy and women known with congenital uterine malformation detected in the previous USG were excluded from the study.
Written informed consent was obtained from the participants. General examination findings and vitals were noted down. After that trans-abdominal uterine artery Doppler assessment was performed by the sonologist at time of the nuchal translucency scan. Uterine artery Doppler indices were measured appropriately. In brief, the paracervical vascular plexus was identified and color Doppler was used to identify the uterine artery as it made its ascent to the uterine body. We used pulsed wave Doppler to obtain uterine artery waveforms. The RI, PI and presence or absence of diastolic notch were assessed in both the uterine arteries.

All the patients were followed routinely. For detection of development of IUGR, criteria used were clinical examination and also from the interval growth rate and from ultrasound. When on clinical examination, there was no adequate interval growth detected and by the ultrasonography, when the fetal weight was less than 10th percentile for that gestational age, IUGR was identified.

\section{Statistical analysis}

All calculations were performed using the SPSS software package (SPSS v10, SPSS Inc., Chicago, IL, USA). For all statistical tests, $\mathrm{p}$ value less than 0.05 was taken to be significant.

\section{RESULTS}

Total of 120 women participated in the study, out of which 4 were lost to follow up. In the remaining 116, the overall prevalence of IUGR was found in 30 participants, that is, $25.8 \%$. The mean uterine artery RI was found to be 0.70 in 30 cases with IUGR compared to 0.67 in 86 cases without IUGR. The first trimester uterine artery RI was significantly associated with prediction of IUGR. P value was found to be 0.0001 (Table 1).

Table 1: Association of RI of uterine arteries with IUGR prediction.

\begin{tabular}{|lllllll|}
\hline RI & $\mathbf{N}$ & Mean RI & Std. deviation & Minimum & Maximum & P value \\
\hline IUGR present & 30 & 0.7023 & 0.04141 & 0.63 & 0.77 & 0.001 \\
\hline IUGR absent & 86 & 0.6722 & 0.04077 & 0.62 & 0.78 & 0.78 \\
\hline Total & 116 & 0.68 & 0.04285 & 0.62 & 0.67 in & \\
\hline
\end{tabular}

The mean uterine artery RI was 0.70 in 30 cases with IUGR and 0.67 in 86 cases without IUGR. The first-trimester uterine artery RI was significantly associated with prediction of IUGR.

Table 2: Association of PI of uterine arteries with IUGR prediction.

\begin{tabular}{|lllllll|}
\hline PI & $\mathbf{N}$ & Mean PI & Std. deviation & Minimum & Maximum & P value \\
\hline IUGR present & 30 & 1.725 & 0.279269 & 1.16 & 2.29 & 0.0001 \\
\hline IUGR absent & 86 & 1.51279 & 0.270745 & 0.95 & 2.25 & \\
\hline Total & 116 & 1.56767 & 0.287328 & 0.95 & 2.29 & \\
\hline
\end{tabular}

The mean uterine artery PI was 1.75 in 30 cases with IUGR and 1.51 in 86 cases without IUGR. The first trimester uterine artery PI was significantly associated with prediction of IUGR. 
Table 3: Association of Doppler status with IUGR.

\begin{tabular}{|llll|}
\hline Doppler status & IUGR (absent) & IUGR (present) & P value \\
\hline Normal & $\mathrm{n}=86$ & $\mathrm{n}=30$ & Chi square $=10.174$ \\
\hline Abnormal & 52 & 8 & P value $=0.00142$ \\
\hline
\end{tabular}

Doppler status was normal in 8 cases with IUGR and abnormal in 22 cases with IUGR. There was a significant association found.

Table 4: Association of notching with IUGR.

\begin{tabular}{|llll|}
\hline Notching & IUGR (absent) & IUGR (present) & P value \\
\hline Present & $\mathrm{n}=86$ & $\mathrm{n}=30$ & Chi square $=0.0061$ \\
\hline Absent & 28 & 10 & P value $=0.937$ \\
\hline
\end{tabular}

The prevalence of first-trimester bilateral uterine artery notches in women who subsequently had IUGR infant (26.3\%) was not significantly associated with that of pregnancies with a normal outcome $(73.6 \%)$.

Table 5: Sensitivity and specificity of various parameters in prediction of IUGR.

\begin{tabular}{|lllll|}
\hline IUGR & Sensitivity $(\%)$ & Specificity $(\%)$ & $\begin{array}{l}\text { Positive predictive } \\
\text { value }(\%)\end{array}$ & $\begin{array}{l}\text { Negative predictive } \\
\text { value }(\%)\end{array}$ \\
\hline Diastolic notch & 33.3 & 67.4 & 25 & 76.3 \\
\hline PI & 56.6 & 84.8 & 56.6 & 85.8 \\
\hline RI & 73.3 & 93 & 78.5 & 90.9 \\
\hline
\end{tabular}

A mean uterine artery RI had a sensitivity of $73.3 \%$ and specificity of $93 \%$ for the prediction of IUGR. A mean uterine artery PI had a sensitivity of $56.6 \%$ and specificity of $84.8 \%$ for the prediction of IUGR. Diastolic notch had least sensitivity $(33.3 \%)$ and specificity $(67.4 \%)$ for prediction of IUGR.

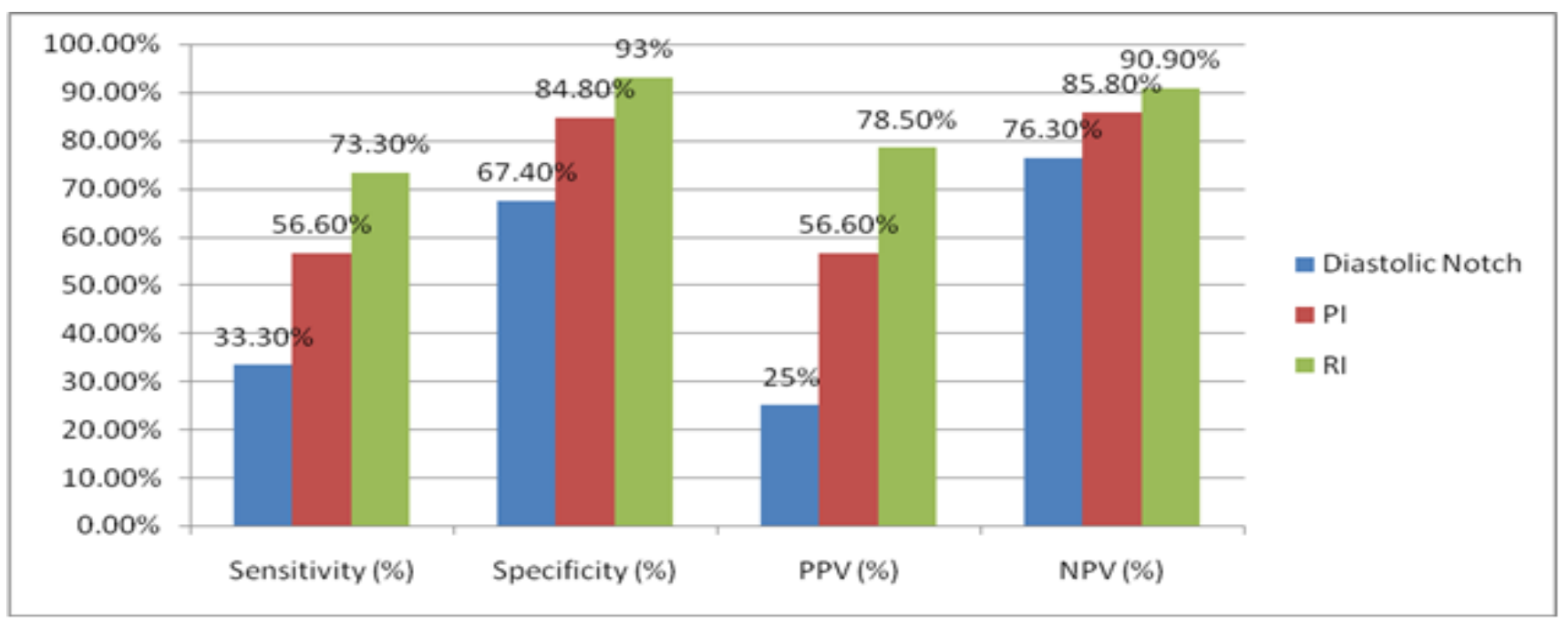

Figure 1: Comparison of sensitivity and specificity.

The mean uterine artery PI was 1.75 in 30 cases with IUGR and 1.51 in 86 cases without IUGR. The first trimester uterine artery PI was significantly associated with prediction of IUGR. P value was found to be 0.0001 (Table 2).

Out of 30 cases with IUGR, 8 cases had normal Doppler study, while 22 cases had abnormal Doppler status. Out of
86 cases without IUGR, 52 cases had normal Doppler study and 34 had abnormal Doppler status. Hence, abnormal Doppler status was significantly associated with prediction of IUGR. P value found to be 0.00142 (Table 3).

10 out of 30 cases with IUGR presented with diastolic notch, while 28 cases out of 86 cases without IUGR 
presented with diastolic notch. The prevalence of firsttrimester bilateral uterine artery notches in women who subsequently had IUGR infant $(33.33 \%)$ was not significantly associated with that of pregnancies with a normal outcome $(32.55 \%)$; p value was found to be 0.937 (Table 4).

A mean uterine artery RI had a sensitivity of $73.3 \%$ and specificity of $93 \%$ for the prediction of IUGR. A mean uterine artery PI had a sensitivity of $56.6 \%$ and specificity of $84.8 \%$ for the prediction of IUGR. Diastolic notch had least sensitivity $(33.3 \%)$ and specificity $(67.4 \%)$ for prediction of IUGR (Table 5).

\section{DISCUSSION}

RI and PI were significantly associated for prediction of IUGR in our study, while notching had no significant association. A few previous studies have prospectively evaluated the role of first-trimester uterine artery Doppler in large populations. ${ }^{19-21}$

The two studies conducted by Gomez et al and Dugoff et al were relatively small and reported modest sensitivities for the prediction of IUGR. ${ }^{19,21}$ Martin et al recruited 3045 women and demonstrated a $12 \%$ sensitivity for SGA (birth weight $<10$ th centile without pre-eclampsia) using a uterine artery PI $>95$ th centile as the cut-off. ${ }^{20}$ They also stratified the SGA population according to gestational age at delivery but they did not report the sensitivity for IUGR.

A large scale study on 3010 women by Melchiorre et al concluded that first-trimester uterine artery mean RI and prevalence of bilateral notching were significantly higher in women destined to deliver SGA neonates than in women with normal pregnancies. ${ }^{22}$

According to the data of our study, the sensitivity of firsttrimester uterine artery Doppler increased from parameters used as diastolic notch, PI and RI $(33.3 \%, 56.6 \%$ and $73.3 \%$ respectively). The improved prediction of firsttrimester uterine artery Doppler for IUGR pregnancy was due to its association with utero-placental insufficiency.

\section{CONCLUSION}

Our study concludes that, first trimester uterine artery RI and PI can be used as a good predictor for IUGR. There is clearly a continuous relationship between uterine artery Doppler indices, specially RI and development of IUGR. Prophylactic measures like administration of low dose aspirin, nutritional supplements, lifestyle modifications, more frequent antenatal visits can be considered at an early stage, the Doppler parameters are found deranged. Doppler ultrasonography is a good non-invasive investigation to assess changes in uteroplacental hemodynamics. However, a sequential ultrasound Doppler analysis in the second trimester at 18-22 weeks would have further increased the sensitivity of the test and false positivity rate could be decreased.
Funding: No funding sources

Conflict of interest: None declared

Ethical approval: The study was approved by the Institutional Ethics Committee

\section{REFERENCES}

1. Sibai B, Dekker G, Kupferminc M. Pre-eclampsia. Lancet. 2005;365(9461):785-99.

2. Khan KS, Wojdyla D, Say L, Gulmezoqlu AM, VanLook PF. WHO analysis of causes of maternal death: a systematic review. Lancet. 2006;367(9516):1066-74.

3. Walker JJ. Pre-eclampsia. Lancet. 2000;356(9237):1260-5.

4. Khong TY, DeWolf F, Robertson WB, Brosens I. Inadequate maternal vascular response to placentation in pregnancies complicated by preeclampsia and by small-for-gestational age infants. $\mathrm{Br} \quad \mathrm{J}$ Obstet Gynaecol. 1986;93(10):1049-59.

5. Pijnenborg R, Anthony J, Davey DA, Rees A, Tiltman A, Vercruysse L, et al. Placental bed spiral arteries in the hypertensive disorders of pregnancy. Br J Obstet Gynaecol. 1991;98(7):648-55.

6. Shanklin DR, Sibai BM. Ultrastructural aspects of pre-eclampsia I: Placental bed and boundary vessels. Am J Obstet Gynecol. 1989;161(3):735-41.

7. Pijnenborg R, Bland JM, Robertson WB, Brosens I. Uteroplacental arterial changes related to interstitial trophoblast migration in early human pregnancy. Placenta. 1983;4(4):397-413.

8. Kam EPY, Gardner L, Loke YW, King A. The role of trophoblast in the physiological change in decidual spiral arteries. Hum Reprod. 1999;14(8):2131-8.

9. Kaufmann P, Black S, Huppertz B. Endovascular trophoblast invasion: implications for the pathogenesis of intrauterine growth retardation and preeclampsia. Biol Reprod. 2003;69(1):1-7.

10. Bower S, Schuchter K, Campbell S. Doppler ultrasound screening as part of routine antenatal scanning: prediction of preeclampsia and intrauterine growth retardation. BJOG. 1993;100(11):989-94.

11. Irion O, Masse J, Forest JC, Moutquin JM. Prediction of preeclampsia, low birthweight for gestation and prematurity by uterine artery blood flow velocity waveforms analysis in low risk nulliparous women. BJOG. 1998;105(4):422-9.

12. Albaiges G, Missfelder-Lobos H, Parra M, Lees C, Cooper D, Nicolaides KH. Comparison of color Doppler uterine artery indices in a population at high risk for adverse outcome at 24 weeks' gestation. Ultrasound Obstet Gynecol. 2003;21(2):170-3.

13. North RA, Ferrier C, Long D, Townsend K, KincaidSmith P. Uterine artery Doppler flow velocity waveforms in the second trimester for the prediction of pre-eclampsia and fetal growth retardation. Obstet Gynecol. 1994;83(3):378-86.

14. Papagerghiou AT, Yu CK, Bindra R, Pandis G, Nicolaides KH. Multicenter screening for preeclampsia and fetal growth restriction by transvaginal 
uterine artery Doppler at 23 weeks of gestation. Ultrasound Obstet Gynecol. 2001;18(5):441-9.

15. Caniggia I, Winter J, Lye SJ, Post M. Oxygen and placental development during the first trimester: implications for the pathophysiology of preeclampsia. Placenta. 2000;21:25-30.

16. Campbell S, Griffin DR, Pearce JM, Recasens TE Cohen-Overbeek, Wilson K, et al. New Doppler technique for assessing uteroplacental blood flow. Lancet. 1983;26:675-7.

17. Trudinger BJ, Giles WB, Cook CM. Uteroplacental blood flow velocity - time waveforms in normal and complicated pregnancy. Br J Obstet and Gynecol. 1985;92:39-45.

18. Ducey J. Complication of hypertension in pregnancy based on Doppler velocimetry. Am. J Obstet Gynecol. 1987;157(3):680-5.

19. Gomez O, Martinez JM, Figueras F, DelRio M, Borobio V, Puerto B, et al. Uterine artery Doppler at 11-14 weeks of gestation to screen for hypertensive disorders and associated complications in an unselected population. Ultrasound Obstet Gynecol. 2005;26(5):490-4.

20. Martin AM, Bindra R, Curcio P, Cicero S, Nicolaides KH. Screening for pre-eclampsia and fetal growth restriction by uterine artery Doppler at 11-14 weeks of gestation. Ultrasound Obstet Gynecol. 2001;18(6):583-6.

21. Dugoff L, Lunch AM, Cioffi-Ragan D, Hobbins JC, Schultz LK, Malone FD, D'Alton ME, for the FASTER Trial Research Consortium. Am J Obstet Gynecol. 2005;193:1208-12.

22. Melchiorre K, Leslie K, Prefumo F, Bhide A, Thilaganathan B. First-trimester uterine artery Doppler indices in the prediction of small-forgestational age pregnancy and intrauterine growth restriction. Ultrasound Obstet Gynecol. 2009;33(5):524-9.

Cite this article as: Gupta U, Agrawal U. Uterine artery Doppler analysis at 11-14 weeks as a predictor of intra-uterine growth restriction. Int J Reprod Contracept Obstet Gynecol 2021;10:4131-5. 